\title{
Learning Robotics for youngsters - The RoboParty Experience
}

\author{
A.Fernando Ribeiro, Gil Lopes, Nino Pereira, José Cruz
}

\begin{abstract}
The involvement of children and adolescents in robotics is on demand by the many events and competitions of robotics all over the world. This non-deterministic world is more attractive, fun, hands-on and with real results than computer virtual simulations and 3D worlds. It is important, by different reasons, to involve people of all ages in an area that some consider the future of mankind and an opportunity to increase the low rate of engineers globally. Robotics competitions at this level are essentially based on teaching motion and programming skills by using Lego ${ }^{\mathrm{TM}}$ based robots and a set of challenges to overcome. This paper presents a different approach that is being used by Minho University in order to attract STEM candidates into these fields, with visible success and excellent results. The event is called RoboParty ${ }^{\circledR}$ and teaches children, adolescents and adults, from any area, how to build a robot from scratch, using electronics, mechanics and programming during three non-stop days.
\end{abstract}

Index Terms-Learning Robotics, STEM, RoboParty, Educational Robotics.

\section{INTRODUCTION}

$\mathrm{R}$ obotics is becoming youngsters desire because it involves the future, technology, and fun. They are everywhere and doing all sort of tasks from industry to services, in health, sports, space travelling, house keeping, etc. Human beings rely more and more on robotic machines as most things are now taken for granted. This creates the interest of young people, to explore and to be engaged sooner on the creation, development and deployment of robotics.

There are many robotics initiatives like First Lego League, RoboCup, Eurobot amongst others, and these are being taken globally in the form of competitions. When young people is involved or a competition refers the word "Junior", it is commonly a Lego ${ }^{\mathrm{TM}}$ based competition where high level programming and Lego assembly bricks, shafts, wheels and chains are used to build a robot in order to accomplish the objectives.

Even though there are some companies developing robotic kits these normally involve only the mechanics and not the electronics, or they come mostly assembled. In some competitions it is recognised that robots end up being assembled and programmed by the teachers or parents, and children are only left to start/stop the robot in the competition field. The competition and children's participation is not focused on the pedagogical side but on competitiveness. Also, the information about the electronics is in most cases not known due to be a proprietary technology.

Although adults alert youngsters to be very careful with electricity because of electrocution risk, this fear of electricity is generally extended to any electronic device and people feel safe to see the electronics inaccessible inside plastic boxes. Exposed electrics and electronics became a myth of a dangerous and harmful thing. In opposition there are children, curious and inquisitive, always trying to know how things are made of and willing to open any plastic box to see the electronics inside.

Teaching children general principles of electronics is a way to make them understand the important aspects of the different electronic components, how they operate, where to touch to avoid electric shocks or to avoid damaging the components. It makes their life easier to deal and to operate with electronic equipment and it entices some enthusiasts on following an engineering career on electronics or robotics.

"Lack of engineers" is a buzzword filling newspapers headlines in the past few years [1, 2], and robotics industry is no exception. The reasons are many but one possible solution is to foster youngster's curiosity and interest for robotics engineering related areas, motivating them to learn in a structured way and forcing them to a hands-on-science experience [3-5]. A pedagogical approach is essential in order to allow their interest on robotics and engineering in general to naturally grow. Postponing this "lack of engineers" problem to future generations will compromise our own future.

The Laboratory of Automation and Robotics (LAR) [6] from University of Minho (Guimaraes - Portugal) [7], has developed mobile autonomous robots and participated on many national and international robotics competitions for the past 12 years, with special attention dedicated to the worldwide robotics challenge RoboCup [8], both on the Middle Size League and RoboCup@Home League.

Also, a large demand for talks and demonstrations in primary and secondary schools from all over the country about robotics has been requested to this group along the years. The robotics subject is on demand by the amount of Hollywood films on this theme, the robotics events announced and shown by the media, the console game industry with appealing games on robotics, the evolution on the industry of toys and their capabilities and the affordable robotic kits available in the shops nowadays. 
The Robotics group at University of Minho has decided to take a step further and motivate youngsters to the robotics field, and instead of helping them competing with robots they invite them to come to the University of Minho in groups of 4 people to learn how to build a small robot. Teams of students with a tutor (teacher, parent or any adult responsible for the team) would get together for three non-stop days in a single event, where they would be taught how to build and program a robot with their own hands, with lectures specially created for their young ages, by experts on robotics. The experience was a complete success and this paper describes this experience.

\section{ROBOPARTY - EDUTAINMENT ROBOTICS}

The event's main objective is to teach robotics to people who have no knowledge on robotics, in an entertaining and fun way, highly practical hands-on approach, in a friendly and helping environment with balanced and decompressing breaks for ludic, entertaining and sports activities. Starting from ages of 11 , the event is being populated by people of all ages but mainly focused at youngsters with a peak at around 16-18 years old.

Participants are guided and supervised by experts on robotics by fostering their enthusiasm in science, technology, engineering and mathematics (STEM) studies, as they only need to bring a sleeping bag, a laptop computer for the team, the desire to learn robotics and a good state of mind. In the end, they take home a mobile robot built by themselves, beginners level knowledge on electronics, programming, mechanics, and a will to continue improving their knowledge on these matters (as well as new friendships, souvenirs from RoboParty, lots of pictures and good memories for a possible new future).

Each team is made of four people, being one of them the team leader, adult and responsible for the whole team. This leader can be a teacher, a parent or any other person who is willing to help the youngsters, willing to also learn and participate in the event fully. The participants are encouraged to share knowledge and ideas with other teams as it has been seen helpful in establishing good links of friendship, exchanging contacts and creating future relations for common projects and robotics events participation.

\section{A. The facilities}

In order to accommodate almost five hundred people including participants, volunteers and staff, a large space was necessary and the event is being held in the University sports hall since its first edition (Fig. 1). Tables are arranged to allow four teams to work in the same workspace. This promotes information sharing between teams encouraging their relationship. Each table has its mains sockets underneath for the laptops and soldering irons.

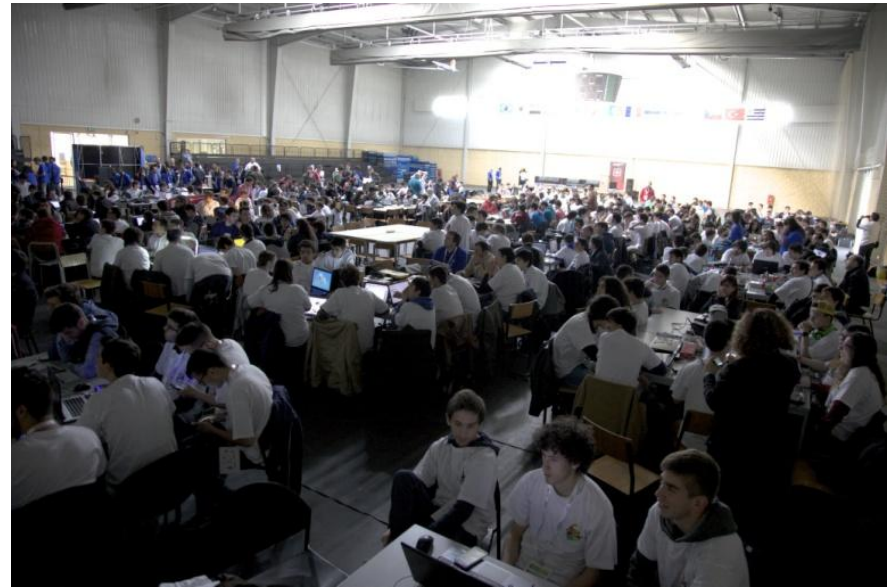

Fig. 1. RoboParty working area in the University sports hall

The working area takes about $2 / 3$ of the overall pavilion area as the other $1 / 3$ is left for multipurpose activities such as entertainment and ludic activities during day and as a sleeping area at night as shown in Fig. 2. Fig. 3 shows a panoramic view of the working area during the event.

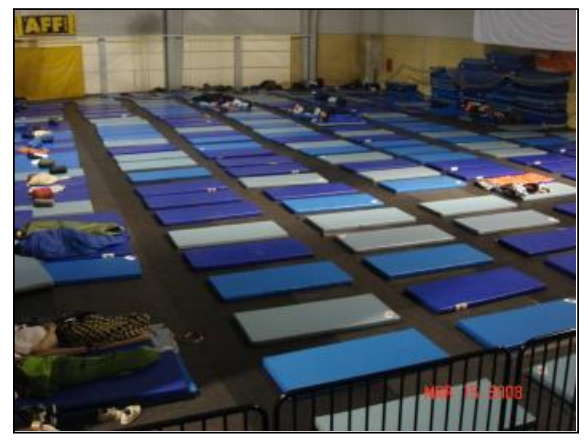

Fig. 2. Multipurpose area used as sleeping area at night

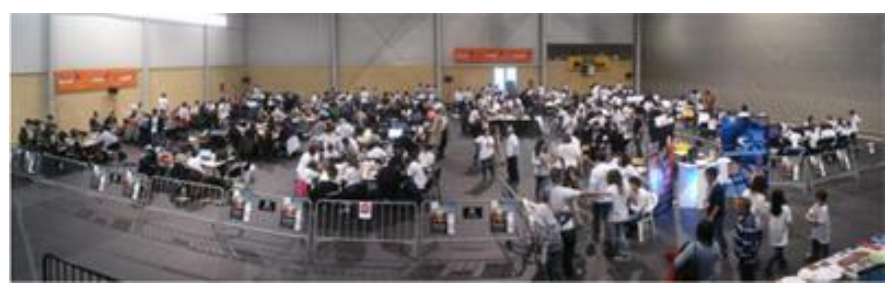

Fig. 3. Panoramic view of the working area during the event

The University sports hall provides good conditions for the type of event such as large space, central heating/air conditioning, toilet facilities for a large amount of people, dressing and shower rooms, spa and sauna area and a fitness lounge. It also provides for security with surveillance cameras, electronic entrance control, file cabinets with lockers and a reception. Outside the building there is a large car parking space.

Nearby, the University canteen provides lunch and dinner meals for the participants as breakfast are provided by the coffee shop next to the sports hall. The spacious University gardens are a good place for relaxation and walking.

For an event like RoboParty a great deal of staff is necessary and is made of a group of over 50 volunteers who provide precious help during the three days of the event. They 
are mainly students of the Industrial Electronics first degree, especially form the last year of their studies.

Lectures on how to build the robot, mechanics, soldering the electronic components, programming, some history of robotics and national and international robotics competitions, servicing robots and other subjects, are taken in the multipurpose area (Fig. 4).

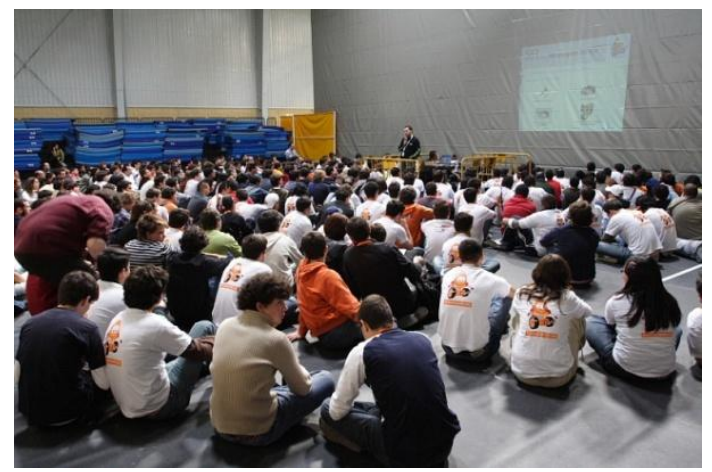

Fig. 4. Participants having lectures on how to build the robot

Robot demonstrations and display of new high-tech gadgets is reserved to a special area next to the working space.

The entertaining/sports activities are very popular; such as the indoor Aircraft Modelling, Basketball, Football, Tennis table, Badminton, Wood Ball, Taekwondo, Yoga, Kickboxing, Judo, Karate, Capoeira, Stretches, Cardio Session, Triathlon indoor, Golf, Quick Chess, circus activities, Ballroom dance, Archery, Horse Riding and Scuba Diving. These activities are available most of the time and each participant decides on which activities is going to participate. Professionals on each activity (indoor or outdoor) are present to follow, guide and teach the participant.

\section{B. The image}

The RoboParty image was created by a professional designer who produced Ruminho (Robotics at University of MINHO), the event's mascot. It consists of a friendly two wheels robot, with two robotic arms and large eyes (Fig. 5). Based on the Ruminho mascot, several products were created (Fig. 6) such as the event's T-shirt offered to all the participants, the RFID badge used for check-in at the working area entrance, some trophies given to the winners on some of the robot trials or sports competitions, the participation certificate, the Ruminho plush and advertising posters (Fig. 5) sent to schools months before.

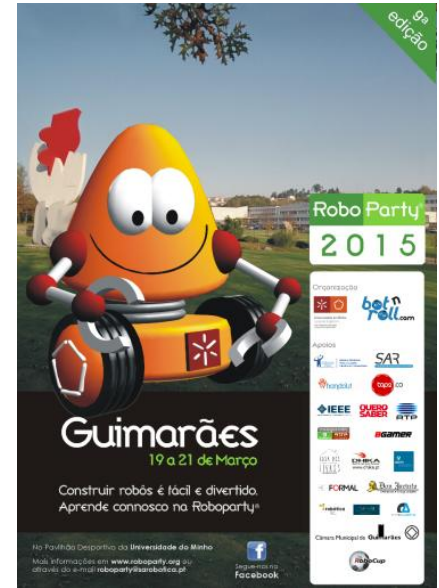

Fig. 5. The official mascot Ruminho of the poster edition 2015
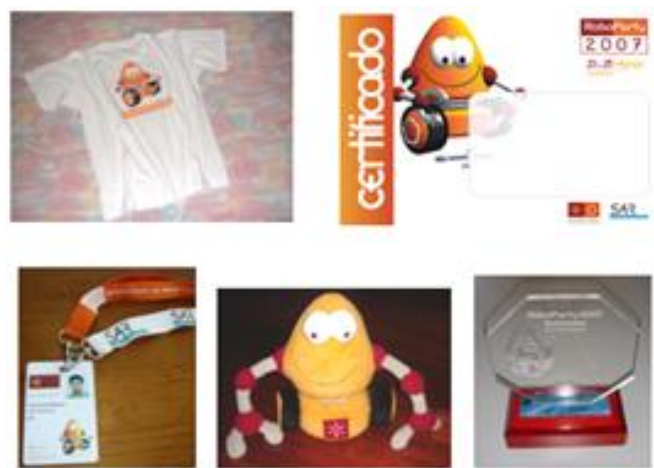

Fig. 6. RoboParty image used in different products

A web site was created [9] to provide all the information related to the event. It also serves to advertise the event and to allow team registrations. Parents and tutors can use the web site to find all the necessary information in order to understand all the procedures involved, security aspects and the rules of the event. The web site also provides pictures and movies of previous editions so people can have an idea of how the event happens. During the event this gallery section of the web site is populated with pictures and movies taken during the day, along with a webcam streaming of the working area so people at home can enjoy the event live as well.

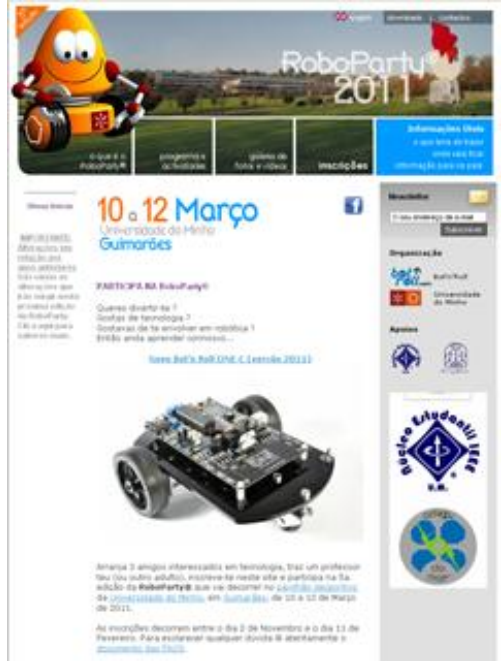

Fig. 7. RoboParty web site front page (edition 2011) 


\section{THE ROBOPARTY EVENT STEP-BY-STEP}

\section{A. The Teaching}

Lectures are given to participants in different stages according to the milestone achieved by the teams. The initial lectures are based on soldering advices and tips, mechanical assembly of the robot and mainly, how to recognize the different electronic components, their polarity if exists and how and where they should fit in the PCB. All the aspects that should be taken in consideration regarding safety, organization and optimization are also referred. This set of lectures is given on the first day, right after the teams receive their robotic kit and they are prepared to be accessible and suitable for the participants' young age. Lectures are provided in an informal environment with the participants sitting on the floor in the multipurpose area as shown in Fig. 4.

In order to increase the participants' knowledge about robotics and other areas of science, two speakers are invited every year to talk about their expertise in their research area. This way, youngsters can become aware of some state of the art robots, ideas and backgrounds. The venue is at the University main auditorium of Azurem Campus.

The most relevant part of the event is the hands-on work of soldering and mechanical assembly of the robot. According to many youngsters this is the part they most like to do. It takes almost one third of the whole event and teams are invited to enrol all the team members in this task. This leads that everyone on the team experiments soldering, handling electronic components, using screwdrivers, pliers and other tools. Tutors can help on these tasks by guiding the team members accordingly to avoid errors, damage of components and hurting themselves by wrongly handling a tool or the soldering iron. Fig. 8 shows two young boys doing the soldering task and dividing the task in two: while one is soldering the components, the other holds the cutting pliers to cut the excess of the component pins. This is common practice in many teams as the way they share the workload of each task. Once in a while they swap positions.

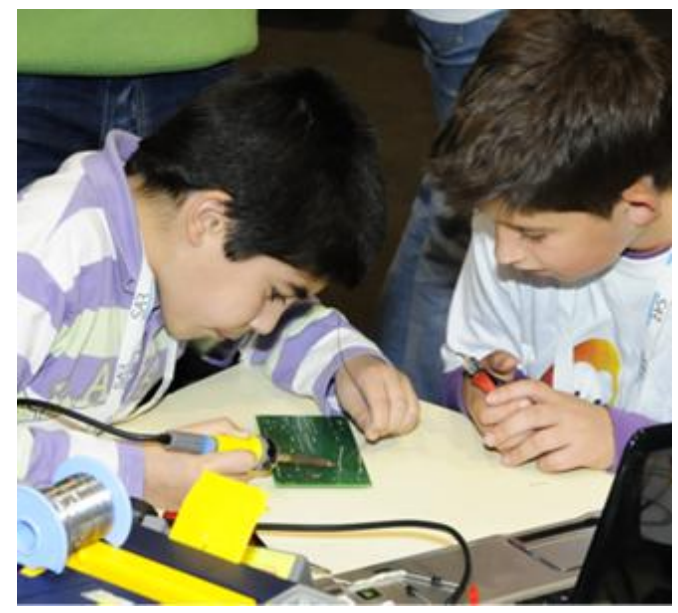

Fig. 8. Two youngsters working on soldering the electronic components, one is soldering and the other cuts the excess of the component pins
Team collaboration and tutoring is very important as referred previously. In order to stimulate team members, tutors should put questions forward to create dialog, sharing of information and subject discussion in the group. Fig. 9 shows an example of this behaviour.

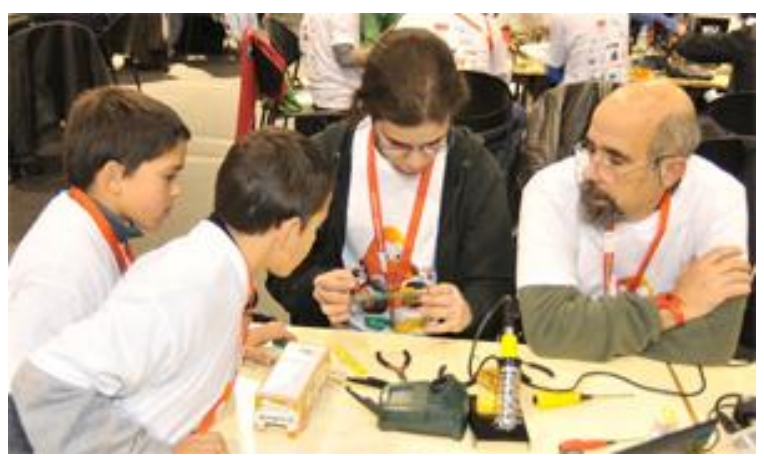

Fig. 9. Questioning to stimulate observation and discussion within the group

Another important aspect to point out on RoboParty is the female participation. It has been observed that the participation of the female gender in RoboParty is increasing, and some teams are majorly female based. Fig. 10 shows an example of a team made of young girls. In the figure a boy from the neighbour team is helping them on the soldering task.

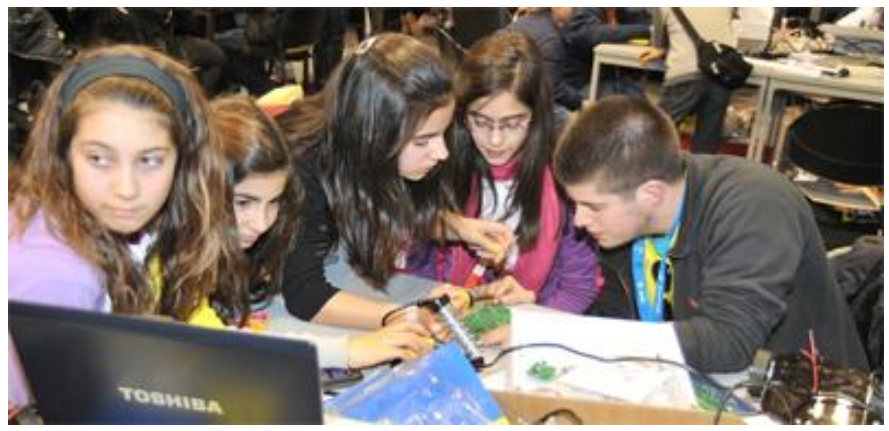

Fig. 10. Team made only of young girls being helped by a boy of the neighbour team

Robot programming is the next task after finishing the soldering and the mechanical parts of the robot. For equity reasons the lectures of programming are only given after the teams have finished building their robot and it is commonly on the second day of the event. This task consists of installing a program on the team's computer that will provide the necessary environment to develop, compile and communicate with the robot to upload the binary code. The language used was BASIC for PICAXE until 2012, but from 2013 onwards the PCB uses an Arduino UNO as the brain.

The first steps to sensor feedback are performed at this stage. 


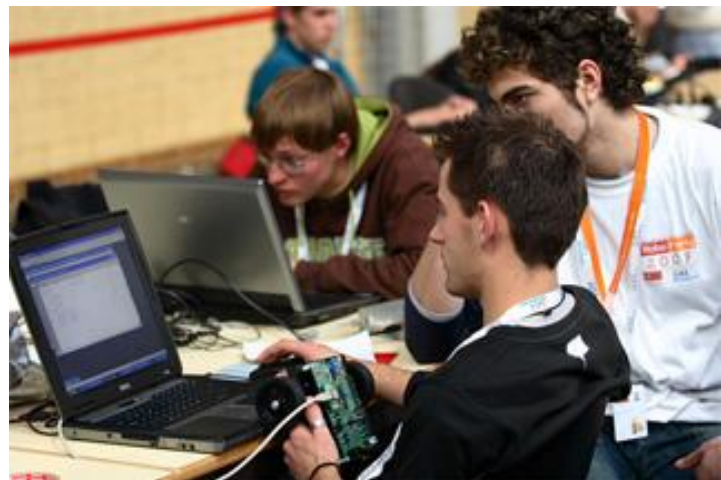

Fig. 11. Participants programming their robot

Fine-tuning the infrared sensor distance is made first using the robot's test program for this sensor. It is at this point that the interaction with an operating robot begins and typically, a sheet of white paper is used to test it. They look like a baby on their first steps by interacting for the first time with a machine and seeing it reacting. Their proud relies on the fact that it was a machine built by them and it is performing well. The test program can sense if the frontal infrared sensor detects an obstacle on the left or on the right side, by rotating the robot wheels in opposition. The eyes of the proud builders shine when the sheet of paper is moved from left to right and they observe a reaction to their action meaning that after all, they have accomplished something.

As a complementary part of the programming lecture, the example code supplied with the robot's CD has demonstrated to be a good guide for the user's first steps. Most teams tend to use this example code and proliferate from there as a starting point, only changing small parts of the code but keeping the basic structure. Their mind for programming is being structured at this time and code reusing is something they embrace easily.

Three tasks are then defined on each team, depending on the extra sensors they acquired with the robotic kit. The first task is to program the robot to perform the obstacle trial, i.e., with the frontal infrared sensors, the robot can be programmed to avoid hitting walls. The obstacle trial is a small circuit, based on walls where the robot must accomplish the circuit without touching the walls at the minimum time possible (Fig. 12). Programming creativity and a bit of luck are the ingredients for this task and youngsters react quite well to the challenge.

\section{B. The robotic kit "Bot'n roll"}

A special purpose robotic kit was developed for this event, by SAR - Solutions for Automation and Robotics [10] and University of Minho. This kit was named Bot'n Roll ONE [11]. The robot assembly has three major steps: mechanics build up, electronics soldering and robot programming. All the necessary parts are in the box. The idea behind the project was to create a small, affordable and expandable robotic kit that even a child could assemble it. The electronic components to be used are discrete and normal size components, such as resistors, capacitor, diodes, voltage regulators and microchips.
The printed-circuit board (PCB) was designed to be easily handled, where the components can be positioned with plenty of space around them. Space was not a constraint but a necessity. This would allow youngsters to learn how to fit the components, soldering and cutting the component's pin extension free of hassles. Some more complex components were supplied as a finished part, namely the communication board. This board contains surface mount components and converts the RS232 signals from the robot's processor to USB signal in order to enable the robot to be connected to a computer. In that case, the board is supplied already assembled and soldered, with the pins ready to be fit into the robot's PCB and soldered afterwards.

The mechanical parts are also easy to assemble. A set of motors and wheels has to be screwed to each other and then screwed to the robot's base. A third caster wheel has also to be screwed to the robot's base in the back of it to make it horizontal.

All the wiring and connectors were thought also to be easy to handle and colourful to avoid any doubts. Some care should be taken and participants are warned of the dangerous of mixing the cables, but no harmful situation occurs if they are mixed but a damaged component. The power switch is positioned in an accessible place and the wires have to be soldered to it. The robot's battery is positioned underneath and supported with Velcro to allow a fast replacement for charging.

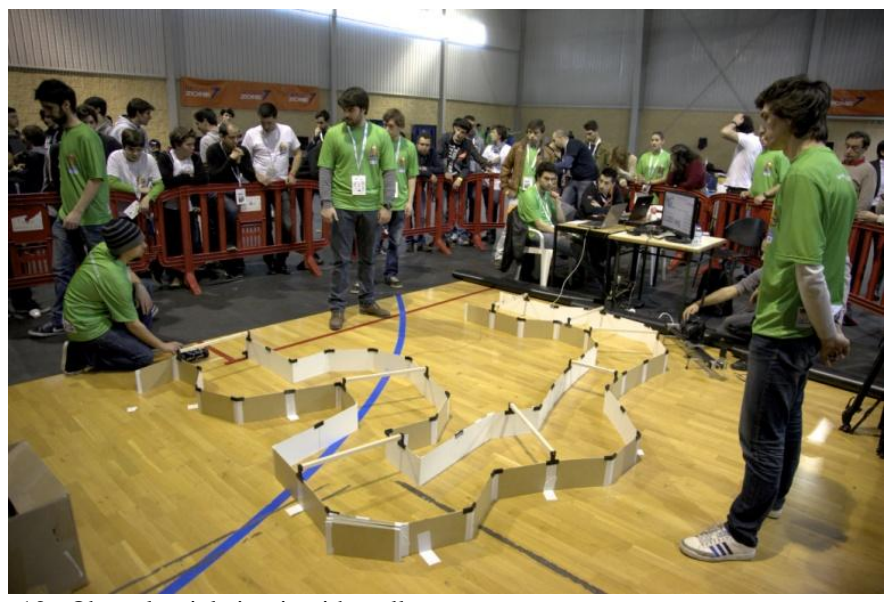

Fig. 12. Obstacle trial circuit with walls

The second task is on the constructive and creative side where the team decorates their robot. Manual skills are very important to attain the intended objectives. Sometimes teams dedicate the time of a single member to the task during the whole event, one that is more skilled in craftsman work. The result can be overwhelming and on the past editions great achievements have been made. Fig. 13 shows some examples of 2009 and 2010 editions of RoboParty. Mechanics are also changed in some cases to adapt the robot to the toy they put on top in order to move an arm or leg synchronised with the wheels, for example. Teams can be very imaginative.

The third task is the dance trial. Programming on this task involves creativity in the sense of choreography. The team is 
allowed to pick a song and to program their robot to the song rhythm. Some teams use for this task the mixture of their robot dressing with a favourite song. All together, with some funny robot movements, the 60 seconds of dance on the stage can make the crowd laugh out loud. This third task makes teams to join the previous tasks into a single one: craftsman work, choreography, robot programming and loads of creativity. Since the working area of the event is open space, and four teams share the same workbench, it is interesting to observe how youngsters learn with each other, copying the best ideas, having their own ideas, in a friendly and peaceful environment.

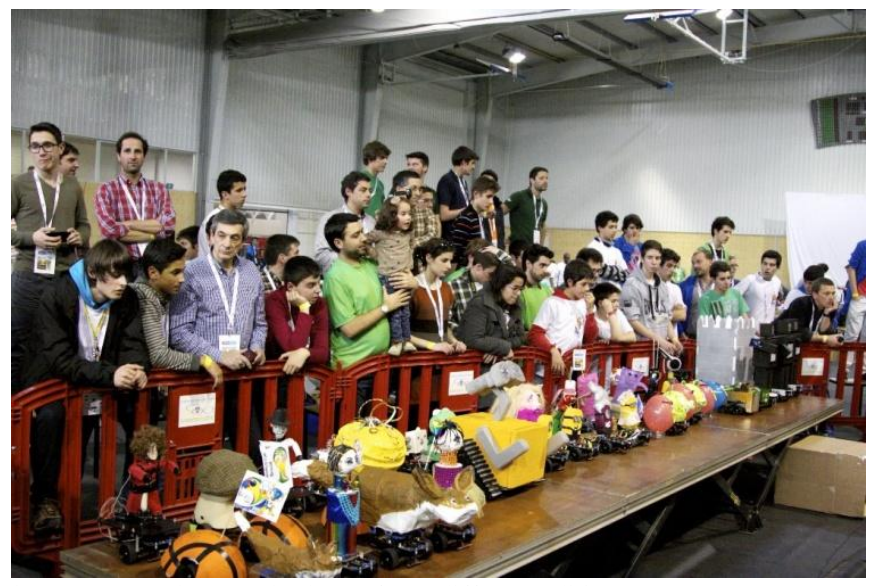

Fig. 13. Some decorated robots of two different editions

A University of Minho spin-off company named SAR Solutions for Automation and Robotics, especially developed the robotic kit for RoboParty. These alumni were aware of the organisation's intention and they helped on the launch and support of this event. Nowadays this robotic kit is commercially available and the company is still involved in the event. At each edition, a workshop is reserved inside the working area where they can provide close support to the needs of the participants. Having such young people handling for the first time of their lives small electronic components, one could expect to have damaged components, bad soldering or a component soldered in the wrong place. SAR company's technicians are there during the whole event as they provide the last resort help to ensure every single robot will work in the end. This is one of the Organisation's assurances to the participants and this has been achieved so far.

The kit contents are all the mechanical and electronic parts to build the robot as shown in Fig. 14. The complete assembled robot with some of the extras is shown in Fig. 15. All the cables and chargers are supplied in the BOX so that the robot can start working immediately. After RoboParty, the robot belongs to the team and they can take it home/school.

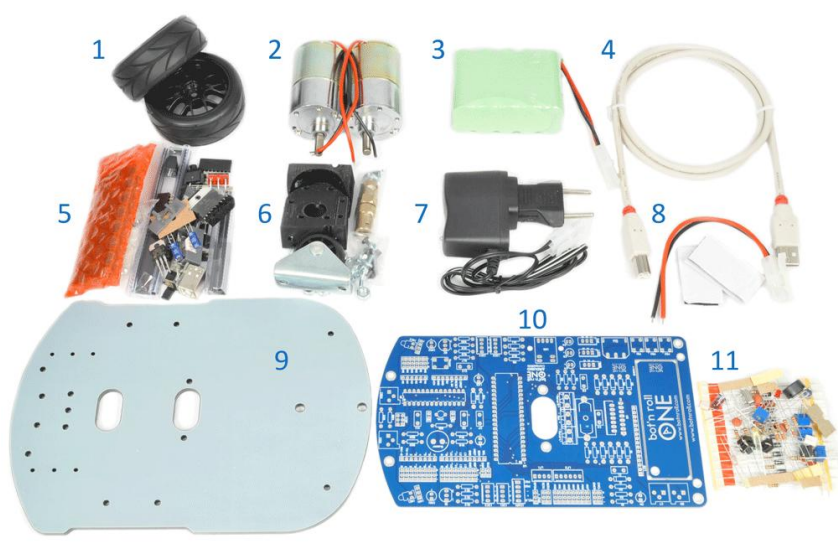

Fig. 14. Bot'n roll robotic kit mechanical and electronic components as supplied in the box

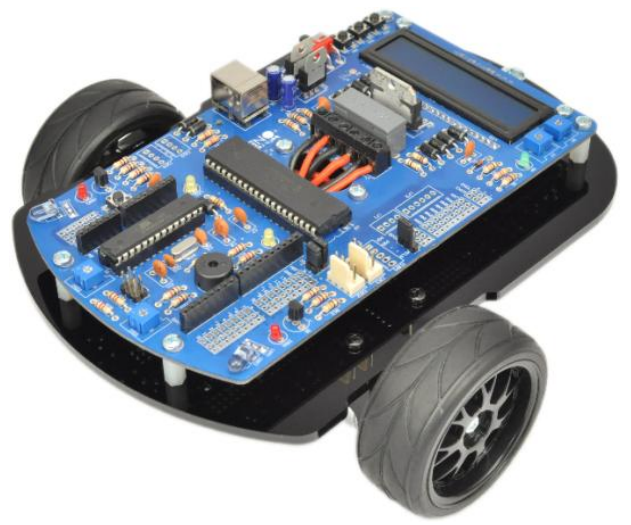

Fig. 15. Bot'n roll robotic kit after fully assembled and with extras

\section{Extra sensors}

The robotic kit comes with the basic frontal infrared sensors allowing the robot to avoid obstacle collision. Some extra sensors designed for the kit can be acquired before or during the event. One very required sensor is the line following. With this sensor, attached underneath, the robot can be programmed to follow a dark line in a contrasting background. Together with obstacle avoidance, the robot becomes a complete autonomous traveller when well programmed. A special track and trial was created in order to allow teams to program and experiment their robot to achieve the best times (Fig. 16).

Other extra sensor available with the robotic kit is a RGB colour sensor that returns a value with the colour read by the sensor. It can also be attached underneath the robot, side by side with the line follower. Teams may use this sensor to increase their capability in the different trials such as the dance trials, where the robot can follow different coloured lines on the floor, allowing a much richer and precise dance performance. Some other add-ons can also be acquired with the robotic kit such as a RGB LED, a loud speaker and a LCD $20 \times 4$ characters display. 


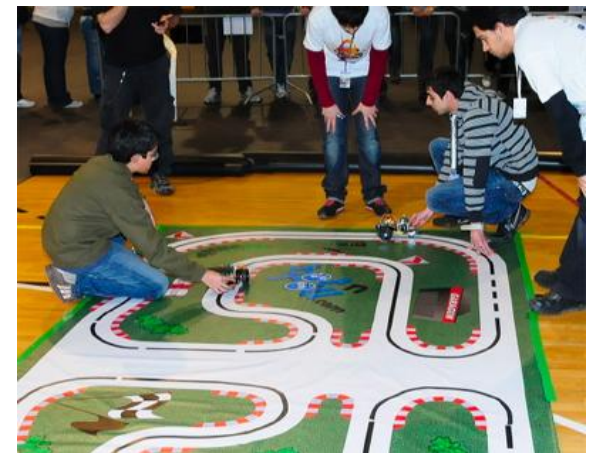

Fig. 16. Track used to test the line following extra sensor of the robotic kit

\section{Entertaining/sports activities}

A non-stop event for three days is exhausting and relaxing moments should exist whenever is possible. Having that in mind, RoboParty has a set of activities that allows the participants to stop what they are doing and to distract themselves with some ludic activities, and in some cases, to be part of those activities. Participation is optional and in some of them participants have to register, for free, due to a possible limitation in the number of people in a particular activity. For the ludic and entertaining activities, they just need to sit down and relax watching. It provides mental relaxation and when they come back to work, all the problems seem to have gone.

Some sports activities are indoor and some are outdoor, if the weather helps. Fig. 17 shows a RoboParty participant, a young boy, learning to play Croquet.

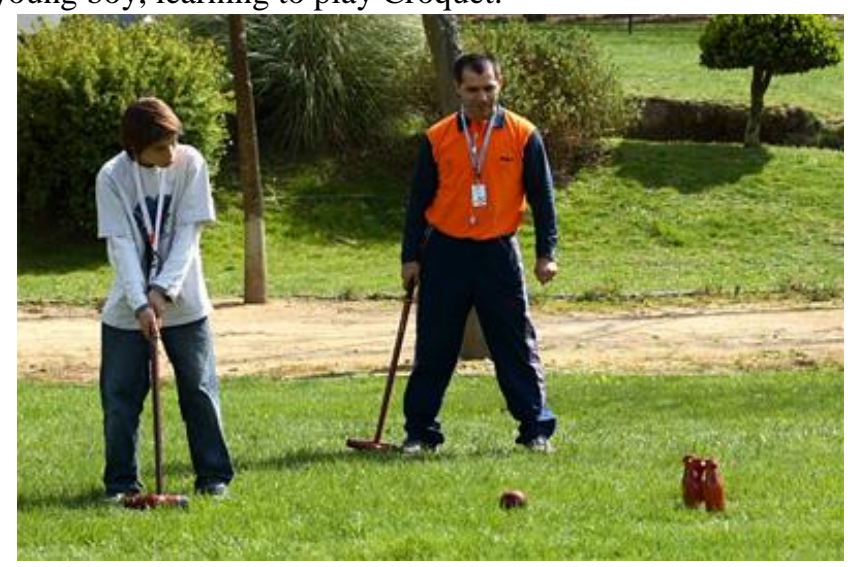

Fig. 17. RoboParty participant learning Croquet as an outdoor activity

The RoboParty Organisation is always trying to bring new and unknown entertainment or sport activities to the event, at least new to the majority of the participants. Scuba diving and horse riding were two activities, for example, that a great majority of the youngsters tried at RoboParty for the first time in their lives. It is an opportunity to practice engineering and robotics together with these activities, in a single event.

\section{Checking in at the event}

Participants are told to bring with them a sleeping bag and a computer for the team. When they arrive on the first day, a bag is provided to the team leader at the check-in desk containing RFID badges each with the participant's passport style photograph to allow them access to the facilities, a RoboParty T-Shirt to each participant, a city map, the program of the event, the robotic Kit and a CD containing the instructions (with a video) on how to build the robot. All under aged participant have to bring a permit form signed by the parents giving them permission to attend the event and the team leader provides this.

Some basic tools are also necessary and apart from the ones supplied with the kit, extra tools such as a soldering iron and pliers must be brought from home, or acquired at the event in the form of a tool kit available as an extra. The web site contains a description of all necessary tools to build up the robot.

\section{E. Help of volunteers}

An event like RoboParty involving more than 400 participants, during 3 non-stop days, needs a good amount of staff. Being a tight budget event, volunteers were the only solution found by the organisation to use as staff members that could guide, help, reply to any calls or necessities the participants may have during the event. This precious help of volunteers is what makes the RoboParty event a success. This task has been performed by the students of the first degree of the Industrial Electronics department of University of Minho, organised by the IEEE student branch of the University. Their help starts before the event, preparing the layout of the work areas and all other things related, and finishes after the event dismantling and tiding up everything. During the event, they are the perfect help to the teams providing a close guidance at the workbench. Since their T-Shirts have different colours they are very easy to spot and teams frequently call them on any question they might have. These volunteers are the first filter or triage for any hardware problem, before taking the robot to the skilled technicians of the company who developed the robot, on their workshop in the working area. These volunteers support the entire party program as they guide people between activities, at lunch and dinner times to the canteen, taking care of the participants as if they were their family. The participants rapidly learn that they have someone in the party to whom they can trust and they do it. In average around 50 volunteers are registered to support the event, some covering the whole event, some covering only parts of it.

\section{RESULTS}

\section{A. Overall results}

Some results can be drawn after four editions of the event. RoboParty Organisation has defined since the beginning that the event can only support a maximum of 100 teams of four people due to lack of space considerations and that value has been achieved every time. Many more are interested in participating and a spare list is managed to cover any team that might give up in the last month preceding the event. In this way the event has always full house creating a fantastic atmosphere during the three days. Participants come from all 
over the country including the Portuguese islands.

As a matter of interest, an increase on the number of teams from the same school has been observed every year. In other words, a school that has participated for the first time with a single team tends to register several teams in the following year. A record breaking was achieved with a school registering nine teams on the same edition. Another interesting aspect is the family participation, not linked to any school. Some families have embraced the RoboParty spirit and participated in the event as a family, to learn about robotics. A special case should be noted by a family of four (parents and two adolescent sons) that live around $400 \mathrm{kms}$ from the venue, participated on four consecutive editions of the event.

RoboParty has been subject to some studies to assess its results. One of them is described on [12].

\section{CONCLUSION}

Every year RoboParty has full house, which makes it very rewarding. Over 2500 different persons already participate and assembled a robot at RoboParty, and learned some concept of electronics, tried out some mechanical assembling and learned how to program a robot (both in BASIC PICAXE and C for Arduino). Around about 1000 robots have been built in the last 9 editions, by participants from all over the country (islands included) and some foreign countries like USA, Denmark, Angola, Ireland, etc.

Participants ranging from 9 years old up to 65 years old, participated with success. And their teachers (adult to accompany the team) come from all knowledge areas like Informatics, History, Gymnastics, English teachers, Philosophy, etc.

Most of the adults responsible from teams come year after year, with different students.

The three days are very tiring but participants leave very happy, carrying on their hands a robot build by themselves, which will permit them to continue their learning process.

The challenges are also very motivating, and make them work hard to have their robots ready and properly working.

Most participants use their robot to participate on National and International robotics events, re-programming their robots, and some teams even achieved very good results nationally and internationally.

All robots leave RoboParty working, since there is a staff team that fixes any major mistakes teams could have made.

This event is proving that it is possible to motivate youngster to STEM areas (Science, Technology, Engineering and Mathematics).

An overview video of RoboParty is available on YouTube on: https://www.youtube.com/watch?v=ke4N7EJMcVY

\section{ACKNOWLEDGMENT}

The RoboParty Organisation wishes to thank the company SAR - Solutions for Automation and Robotics, who have made all efforts in developing this project, the University of
Minho and especially all the staff from the sports hall, which whom the organisation of the event would be impossible and to the IEEE student branch at Minho University and their volunteers our deep appreciation for their time and efforts in all the support for this event.

\section{REFERENCES}

[1]. Still lack of 36,000 engineers in Germany in German Economy section.2009, [online], Available: http://just4business.eu/2009/06/still-lack-of-36000-engineers-ingermany/.

[2]. Wilson, R. Lack of engineers threatens UK economy. Electronics Weekly.com,2007, [online], Available: http://www.electronicsweekly.com/Articles/2007/07/12/41796/Lac k-of-engineers-threatens-UK-economy.htm.

[3]. Ribeiro, F., Building a robot to use in school : teachers and students learning together, in Formal and informal science education : proceedings of the International Conference on Handson Science (HSCI 2008): Olinda-Recife, Brazil.

[4]. Ribeiro, F., New ways to learn science with enjoyment : robotics as a challenge, in Science for all, quest for excellence : proceedings of the International Conference on Hands-on Science (HSCI 2009): Ahmedabad, Índia.

[5]. Ribeiro, F. and G. Lopes, Summer on Campus - Learning Robotics with fun, in Bridging the Science and Society gap - 7th International Conference on Hands-on Science (HSCI 2010): Rethymno - Greece.

[6]. Laboratory of Automation and Robotics.2009, [online], Available: http://www.robotica.dei.uminho.pt.

[7]. University of Minho.2009, [online], Available: http://www.uminho.pt.

[8]. RoboCup Federation.2010, [online], Available: http://www.robocup.org.

[9]. RoboParty.2010, [online], Available: www.roboparty.org.

[10]. SAR - Solutions for Automation and Robotics. [online], Available: http://www.sarobotica.pt/.

[11]. Bot'n roll One - The RoboParty robot. [online], Available: http://www.botnroll.com/.

[12]. Filomena Soares, Celina Leão, S. Santos, F. Ribeiro, G. Lopes , "An Early Start in Robotics - K-12 Case-Study", International Journal of Engineering Pedagogy (iJEP), Vol. 1, no. 1, 2011, pp. 50-56. 